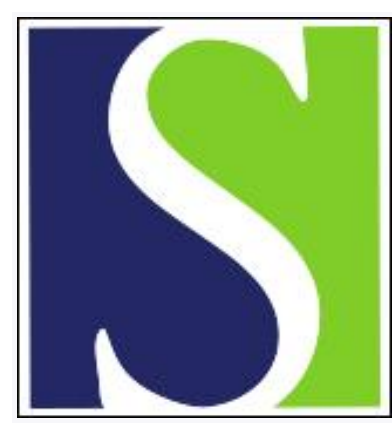

Scand J Work Environ Health 1991;17(2):133-138

https://doi.org/10.5271/sjweh.1724

Issue date: Apr 1991

Comparison of methods for the biomonitoring of nurses handling antitumor drugs.

by Thiringer G, Granung G, Holmen A, Hogstedt B, Jarvholm B, Jonsson D, Persson L, Wahlström J, Westin J

Affiliation: Department of Occupational Medicine, Sahlgrenska Hospital, Goteborg, Sweden.

This article in PubMed: www.ncbi.nlm.nih.gov/pubmed/2047815

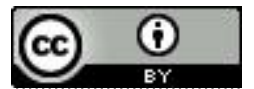




\title{
Comparison of methods for the biomonitoring of nurses handling antitumor drugs
}

\author{
by Gunnar Thiringer, MD, ${ }^{1}$ Gerd Granung RN, ${ }^{1}$ Anders Holmén, MSc, ${ }^{2}$ Benkt Högstedt, MD, ${ }^{2}$ \\ Bengt Järvholm, MD, ${ }^{1}$ Dagmar Jönsson, MD, ${ }^{3}$ Lennart Persson, ${ }^{4}$ Jan Wahlström, MD, ${ }^{5}$ \\ Jan Westin, $M^{6}$
}

\begin{abstract}
THIRINGER G, GRANUNG G, HOLMÉN A, HÖGSTEDT B, JÄRVHOLM B, JÖNSSON D, PERSSON L, WAHLSTRÖM J, WESTIN J. Comparison of methods for the biomonitoring of nurses handling antitumor drugs. Scand J Work Environ Health 1991; 17:133-8. Urinary mutagenicity, thioethers in urine, and sister chromatid exchanges and micronuclei in peripheral lymphocytes were determined for 60 nurses handling cytostatic drugs and 60 referents matched for sex, age, and smoking habits. Safety hoods were used by most of the nurses. The exposed nurses had more sister chromatid exchanges and higher urinary mutagenicity, as measured by Salmonella typhimurium TA 98, than the referents. There were no differences in the other tests. No dose-response relationship was established for any parameter. It was concluded that urinary mutagenicity with the Salmonella strain is the most sensitive test for monitoring nurses handling cytostatic drugs. Determining sister chromatid exchanges may also be a viable test, but it has the drawback of uncertainty as to whether the changes are attributable to present or past exposure. Only comparisons of rather large groups are useful, and a study design requiring matched referents would seem to be optimal.
\end{abstract}

Key terms: cytostatics, micronuclei, sister chromatid exchanges, thioethers, urinary mutagenicity.

Antitumor drugs have been reported to increase the number of chromosome aberrations, sister chromatid exchanges, point mutations, and micronuclei in lymphocytes, and also to increase urinary mutagenicity and thioether excretion, in nurses handling such material $(1-14)$. The health hazards related to these findings are unknown. The various tests may therefore simply be regarded as methods for the biomonitoring of exposure to cytostatic drugs. Few studies have focused on the possibilities of using these methods to prove the absence of exposure or low exposure. A study by Anderson et al (1) on six nurses indicated that the use of proper safety hoods would lead to undetectable levels of urinary mutagenicity. In a study of 12 persons handling cytostatics with protective equipment, Kolmodin-Hedman et al (7) concluded that the use of safety hoods, gloves, masks, protective cuffs, and protective gowns would be satisfactory protection against mutagenic activity in urine. However, to prove that protective measures are sufficient, it is necessary to

1 Department of Occupational Medicine, Sahlgrenska Hospital, Göteborg, Sweden.

2 Department of Occupational Medicine, Länsjukhuset Halmstad, Sweden.

3 The Municipal of Gothenburg Administration Health Care, Annedalsklinikerna, Göteborg, Sweden.

${ }^{4}$ Swedish Laboratory Service Ltd, Halmstad, Sweden.

5 Department of Clinical Genetics, Östra Hospital, Göteborg, Sweden.

${ }^{6}$ Department of Medicine, Sahlgrenska Hospital, Göteborg, Sweden.

Reprint requests to: Dr B Järvholm, Department of Occupational Medicine, Sahlgrenska Hospital, St Sigfridsgatan 85, S-412 66 Göteborg, Sweden. study large groups, especially when the methods have a high coefficient of variation, as do the tests mentioned.

In the early 1980 s measures were undertaken to improve the protection of nurses handling cytostatic drugs in the hospitals of Göteborg. The aim of the present study was to show that these protective measures were sufficient (ie, tests of the type mentioned were expected to indicate that the nurses had no exposure to cytostatic drugs). We therefore investigated nurses handling antitumor drugs with regard to the prevalence of sister chromatid exchanges and micronuclei in lymphocytes, urinary mutagenicity, and thioether excretion. These nurses were compared with matched referents. Furthermore, we looked for a possible dose-response relationship among the exposed nurses and studied the results from certain tests before and after some days of exposure. The objective of this paper is to discuss the sensitivity of the different tests with respect to the biomonitoring of personnel exposed to cytostatics in hospitals.

\section{Subjects and methods}

Our intention was to include all nurses who regularly handled cytostatic drugs in 1984 at the two major hospitals in Göteborg. Most of these nurses were employed in the departments of oncology or hematology. They were invited to participate at a personnel information meeting held in the departments. There were no refusals. A total of 68 nurses participated. For each of these nurses a reference nurse was selected from the 
medical wards. Matching included age ( \pm 5 years), sex, and smoking habits (nonsmoker, ex-smoker, smoker $<10$ cigarettes/d, and smoker $\geq 10$ cigarettes/d). In eight cases we were unable to find a suitable referent, and therefore the final analysis included 60 pairs (table 1).

Each nurse filled out a questionnaire about smoking habits, diseases, use of drugs, allergy, symptoms of the skin, eyes or airways, pregnancy outcome, handling of cytostatic drugs (times, hours and days per week, the names of the drugs, number of years handling the drugs), and the use of protective equipment (gloves, masks, safety hoods, gowns, eye glasses).

Peripheral blood samples were taken from the exposed and reference nurses by venipuncture after a few days of work (usually Thursdays); they were sent to the laboratories the same day for the determination of sister chromatid exchanges and micronuclei in the lymphocytes. Urine samples were taken on the same day for the analysis of urinary mutagenicity and the excretion of thioethers; these samples were kept frozen until the analysis. For the nurses handling cytostatic drugs, urine samples were also taken after at least $2 \mathrm{~d}$ free from the handling of antitumor drugs (usually Mondays). In a few instances the analyses of the blood or urine samples were unsuccessful, for technical reasons. All of the blood and urine samples were analyzed without the analyst's knowing whether the sample originated from a nurse handling cytostatics or from a referent.

\section{Micronuclei in lymphocytes}

For the analysis of micronuclei, blood cultures were stimulated with phytohemagglutinin and incubated for $80 \mathrm{~h}$. For the micronuclei determination 1000 lymphocytes were scored. A micronucleus was defined as a well-demarcated structure similar to the nucleus and less than one-third the size of a normal nucleus (15).

\section{Sister chromatid exchanges in lymphocytes}

For the analysis of sister chromatid exchanges, lymphocytes were cultured for $72 \mathrm{~h}$ with phytohemagglutinin and bromodeoxyuridine. Slides were prepared and incubated with Hoechts $33258^{\circledR}$ for $20 \mathrm{~min}$. After $60 \mathrm{~min}$ of ultraviolet irradiation the slides were stained with Giemsa. Twenty mitoses were analyzed, and the number of sister chromatid exchanges was noted after each cell (16).

\section{Urinary mutagenicity}

We closely followed the bacterial fluctuation test described by Falck (17) for the assay of urinary mutagenicity. The urine was filtered and concentrated by the passing of $100 \mathrm{ml}$ of urine through a column filled with XAD-2 resin. The adsorbed substances were eluted with acetone. After evaporation, the residue was dissolved in dimethyl sulfoxide and kept frozen at $-70^{\circ} \mathrm{C}$ until the analysis. The fluctuation test was performed with the addition of S9-mix with the use of two bacterial strains, Salmonella typhimurium TA 98 and Escherichia coli WP2 uvrA. The possible effect of histidine in the urinary samples was controlled with a preincubation modification of the Salmonella fluctuation test according to O'Connor et al (18). Three dilutions of the urine were tested for mutagenic activity, and the mutagenic activity was calculated in the following way:

(number of revertants in sample - number of revertants in blank)/creatinine (in millimoles) in the sample.

Negative results were registered as zero. The maximum mutagenic activity was used for the statistical calculations.

\section{Urinary thioethers}

For the analysis of thioethers in urine we used a method described by van Doorn et al (19). The urine was acidified and extracted with ethyl acetate. The extract was evaporated, and the residue resolved in ascorbic acid. After the alkaline hydrolysis 5,5'-dithiobis (2-nitrobenzoic acid) (DTNB) was added. DTNB reacts with free $\mathrm{SH}$ groups to yield a yellow color. The absorbance was read in a spectrophotometer at $412 \mathrm{~nm}$. N-acetyll-cysteine was used to prepare a standard curve for the quantitative analysis of thioethers in the urine samples. The findings were expressed as millimoles of thioethers per mole of creatinine so that differences in the concentration of urine could be adjusted for.

\section{Exposure}

In 1982, working instructions regarding the handling of cytostatic drugs were developed at one of the hospitals. The other hospital adopted these instructions about one year later. All of the nurses reported that they had been informed of these instructions. All of the departments using cytostatic drugs had safety

Table 1. Characteristics of the nurses handling cytostatic drugs and the referents.

\begin{tabular}{|c|c|c|c|c|c|c|c|}
\hline & \multirow{2}{*}{$N$} & \multicolumn{2}{|c|}{ Sex } & \multirow{2}{*}{$\begin{array}{l}\text { Mean } \\
\text { age } \\
\text { (years) }\end{array}$} & \multirow{2}{*}{$\begin{array}{c}\text { Smokers } \\
(\%)\end{array}$} & \multirow{2}{*}{$\begin{array}{c}\text { Ex-smokers } \\
(\%)\end{array}$} & \multirow{2}{*}{$\begin{array}{c}\text { Non- } \\
\text { smokers } \\
(\%)\end{array}$} \\
\hline & & Male & Female & & & & \\
\hline $\begin{array}{l}\text { Nurses handling } \\
\text { cytostatic drugs }\end{array}$ & 60 & 2 & 58 & 31.2 & $38^{a}$ & 10 & 52 \\
\hline Referents & 60 & 2 & 58 & 31.7 & $38^{\mathrm{a}}$ & 10 & 52 \\
\hline
\end{tabular}

a Grams of tobacco per day: 10.9 for the nurses handling cytostatic drugs and 11.0 for the referents. 
hoods. Ninety one percent of the nurses reported that they always used the hood, while the remainder used it between 76 and $99 \%$ of the time. All but one nurse always used gloves. The use of paper masks varied from "always" ( $39 \%)$ to "never" ( $29 \%)$.

\section{Statistical methods}

Since the distribution of some of the parameters was rather skewed, the differences between the groups were tested with a nonparametric test (ie, the Wilcoxon signed rank test). Only P-values below 0.05 have been indicated. The dependence on exposure time within the exposed group was described with a linear multivariate model, and the deviation of the coefficients from unity was tested with a t-test. The calculations were performed on a computer using SAS (statistical analysis system) program packages.

\section{Results}

\section{Exposed nurses versus referents}

The nurses handling cytostatics had a significantly higher number of sister chromatid exchanges and more mutagenic activity, as measured by TA 98 , in their urine than the referents (table 2). However, the ranges were wide and almost totally overlapping between the exposed nurses and referents. The frequency of micronuclei, the excretion of thioethers, and the urinary mutagenicity measured by $E$ coli did not differ significantly between the groups (table 2). Smoking referents had an average frequency of sister chromatid exchanges that was $8 \%$ higher than that of the nonsmoking referents. They also had a $110 \%$ higher urinary mutagenicity (TA 98 ) and a $39 \%$ higher excretion of thioethers.

\section{Pre- and postexposure samples}

There were no differences in urinary mutagenicity or thioether excretion before and after cytostatics were handled (table 3). The intraindividual ranges were wide.

\section{Dose-response}

A multivariate linear regression analysis did not indicate an association between exposure to cytostatics and outcome in the tests among nurses handling cytostatic drugs (table 4). There was a borderline significance for sister chromatid exchanges, measuring exposure as times of handling cytostatics per week. Neither could we find any differences in the tests between different departments, the use of protective equipment, or the handling of different cytostatic drugs. In this analysis the drugs were classified into alkylating substances, antimetabolites, antibiotics, mitotic inhibitors, and others. Most nurses had handled several drugs (mean = 4 drugs).

\section{Discussion}

The nurses handled cytostatic drugs in safety hoods and used gloves, and these practices make it difficult

Table 2. Results of the tests comparing the nurses handling cytostatic drugs with the matched referents. ${ }^{a}$ (creat $=$ creatinine)

\begin{tabular}{|c|c|c|c|c|c|c|c|c|c|c|}
\hline & \multirow{2}{*}{\multicolumn{2}{|c|}{$\begin{array}{l}\text { Sister chromatid } \\
\text { exchanges } \\
\text { (per cell) }\end{array}$}} & \multirow{2}{*}{\multicolumn{2}{|c|}{$\begin{array}{l}\text { Micronuclei } \\
\text { (per } 10^{3} \text { cells) }\end{array}$}} & \multicolumn{4}{|c|}{ Urinary mutagenicity } & \multirow{2}{*}{\multicolumn{2}{|c|}{$\begin{array}{c}\text { Thioethers } \\
\text { (mmol/mol creat) }\end{array}$}} \\
\hline & & & & & $\begin{array}{c}\text { Saln } \\
\text { typhi } \\
\mathrm{T}\end{array}$ & $\begin{array}{l}\text { monella } \\
\text { murium } \\
\text { A } 98\end{array}$ & Escher & richia coli & & \\
\hline & Mean & Range & Mean & Range & Median & Range & Median & Range & Median & Range \\
\hline $\begin{array}{l}\text { Nurses handling } \\
\text { cytostatic drugs }\end{array}$ & $6.4^{*}$ & $3.8-9.5$ & 3.0 & $0-9$ & $2476^{* *}$ & $0-49450$ & 279 & $0-21739$ & 4.0 & $0.9-20.1$ \\
\hline Referents & 6.0 & $3.0-9.8$ & 2.9 & $0-8$ & 197 & $0-71524$ & 250 & $0-15669$ & 4.4 & $1.3-28.6$ \\
\hline
\end{tabular}

a Number of pairs: 54 for the sister chromatid exchanges, micronuclei, and Escherichia coli; 51 for the Salmonella typhimurium TA 98 , and 56 for the thioethers.

* $\mathrm{P}<0.05,{ }^{\star \star} \mathrm{P}<0.01$, compared with the matched referents.

Table 3. Urinary mutagenicity and thioether excretion in urine before and after the handling of cytostatic drugs. (creat $=$ creatinine)

\begin{tabular}{|c|c|c|c|c|c|}
\hline \multirow{2}{*}{ Test } & \multirow{2}{*}{$N$} & \multicolumn{2}{|c|}{ Differences after-before exposure } & \multicolumn{2}{|c|}{ Highest value ${ }^{a}$} \\
\hline & & Mean & Range & After & Before \\
\hline \multicolumn{6}{|l|}{$\begin{array}{l}\text { Urinary mutagenicity (maximal } \\
\text { mutagenicity/mmol creat) }\end{array}$} \\
\hline $\begin{array}{l}\text { Salmonella typhimurium TA } 98 \\
\text { Escherichia coli }\end{array}$ & $\begin{array}{l}51 \\
53\end{array}$ & $\begin{array}{r}2836 \\
492\end{array}$ & $\begin{array}{r}-40792-44588 \\
-3915-17795\end{array}$ & $\begin{array}{l}26 \\
22\end{array}$ & $\begin{array}{l}23 \\
23\end{array}$ \\
\hline Thioethers (mmol/mol creat) & 54 & 0.34 & $-6.1-11.7$ & 27 & 26 \\
\hline
\end{tabular}

a Number of persons with highest value after or before the handling of cytostatic drugs. 
Table 4. Multivariate linear regression analysis of the relationship between the outcome of tests and the handling of cytostatics (exposure) with adjustment for age and actual smoking habits. ( $S C E=A+B \times(g$ tobacco/d) $+C \times$ age $+D \times$ exposure; exposure to cytostatics was measured in times/week, hours/day or days/week). The coefficient (D) for different measures of intensity of exposure is presented in the table. (SEM = standard error of the mean, creat = creatinine)

\begin{tabular}{|c|c|c|c|c|c|c|}
\hline & \multicolumn{2}{|c|}{ Times/week } & \multicolumn{2}{|c|}{ Hours/day } & \multicolumn{2}{|c|}{ Days/week } \\
\hline & Coefficient & SEM & Coefficient & SEM & Coefficient & SEM \\
\hline SCE (per cell) & $0.19^{*}$ & 0.09 & 0.22 & 0.17 & 0.20 & 0.17 \\
\hline Micronuclei (per $10^{3}$ cells) & -0.03 & 0.17 & 0.42 & 0.32 & 0.51 & 0.30 \\
\hline \multicolumn{7}{|l|}{$\begin{array}{l}\text { Urinary mutagenicity (maximal } \\
\text { mutagenicity/mmol creat) }\end{array}$} \\
\hline $\begin{array}{l}\text { Salmonella typhimurium TA } 98 \\
\text { Escherichia coli }\end{array}$ & $\begin{array}{r}-374 \\
48\end{array}$ & $\begin{array}{l}843 \\
229\end{array}$ & $\begin{array}{r}-3250 \\
-592\end{array}$ & $\begin{array}{r}1753 \\
475\end{array}$ & $\begin{array}{r}-2070 \\
514\end{array}$ & $\begin{array}{r}1637 \\
447\end{array}$ \\
\hline Thioethers (mmol/mol creat) & 0.11 & 0.26 & -0.06 & 0.51 & 0.55 & 0.48 \\
\hline
\end{tabular}

* $P<0.05$; coefficient different from 0 ; t-test.

to understand how they could have been exposed to any drugs at all. Anderson et al (1) showed that safety hoods with a vertical laminar flow give good protection, while hoods with a horizontal flow do not. The hoods used by these nurses did not always satisfy the requirements of optimal flow according to Anderson. In some instances we also found leaks in the hoods. Some drugs are delivered in bottles with excess pressure. When a needle is inserted through the rubber membrane, air compressed with the cytostatics may aerosolize and come into the breathing zone of the nurse. The filter mask used by these nurses did not totally protect them from such exposure.

Sister chromatid exchanges and micronuclei reflected effects on the chromosomes. The urine tests measured exposure to substances with mutagenic potential. The increased frequency of sister chromatid exchanges and urinary mutagenicity indicated that the nurses handling cytostatic drugs had an increased exposure to potentially genotoxic substances. The health impact of this exposure is unknown (20), but some studies indicate that nurses exposed to cytostatic drugs have an excess frequency of fetal loss and of malformations in their offspring $(21,22)$. Although the matching was good in terms of smoking habits and age between the nurses handling cytostatic drugs and the referents, we cannot entirely exclude the possibility that the differences in sister chromatid exchanges and urinary mutagenicity were attributable to factors other than exposure to cytostatic drugs. Since smoking may be a strong confounder for some tests, misclassification of smoking habits may be a problem. An underreporting of smoking habits may have occurred, but there was no reason for the nurses handling cytostatic drugs to have reported their smoking habits more incorrectly than the referents.

The possibility of using urinary mutagenicity or cytogenetic methods for the biomonitoring of occupational exposure to cytostatic drugs has previously been discussed by Sorsa et al (20). However, they did not compare different tests or discuss the optimal design of a study. A correlation between all tests is not to be expected, as they measure different end points. This study indicates that sister chromatid exchanges and urinary mutagenicity with Salmonella typhimurium TA 98 are the tests with the highest sensitivity for detecting exposure to cytostatic drugs. A comparison of the results of these tests between exposed nurses and referents seems to be more sensitive than postshift-preshift determination or a comparison between nurses with high and low exposure (dose-response). The difference in sister chromatid exchanges between exposed nurses and referents may be an effect of past rather than current exposure (23). Urinary mutagenicity, on the other hand, reflects recent exposure.

The other tests, urinary mutagenicity with $E$ coli, micronuclei and the excretion of thioethers, appear to be less sensitive. Only in a few studies have several tests been used, and in most of them only small groups have been investigated. Pohlova et al (11) studied 38 persons exposed to cytostatic drugs in chemical laboratories. They found an increased frequency of chromosome aberrations, sister chromatid exchanges, and urinary mutagenicity (TA 98) as compared with unmatched referents $(\mathrm{N}=19)$. Stucker et al (12) studied 17 nurses handling cytostatic drugs and unmatched referents. There were no differences in the occurrence of chromosome aberrations or sister chromatid exchanges between the groups, while urinary mutagenicity (TA $98+$ S9) was higher in the exposed group. Sorsa et al (23) studied production workers $(\mathrm{N}=32)$ and hospital workers $(\mathrm{N}=47)$ exposed to cyclophosphamide. They were, however, unable to detect any significant differences in the occurrence of sister chromatid exchanges, urinary mutagenicity (TA 100, TA 1535), chromosome aberrations, or micronuclei, as compared with the levels of the unmatched referents. In our study we did not use chromosome aberrations, as the method is too expensive for screening large groups and is therefore not suitable for biomonitoring.

Some studies of persons using unsatisfactory protective equipment have shown a difference in the postshift-preshift thioether excretion and urinary mutagenicity $(6-8)$. However, there was very high in- 
dividual variability that indicated that other factors are important determinants for the outcome of this parameter. It is thus difficult to detect slight variations attributable to the handling of cytostatic drugs. The multivariate analysis indicated that only a small part of the variability in urinary mutagenicity can be explained in terms of age, smoking, and exposure to cytostatic drugs $\left(R^{2} \leq 0.2\right)$. This finding may also explain why we could not detect any dose-response relationship.

Of the tests studied, urinary mutagenicity with Salmonella typhimurium TA 98 and sister chromatid exchanges seem to be the most suitable for the biomonitoring of nurses handling cytostatic drugs. The use of sister chromatid exchanges has the drawback of uncertainty as to whether the changes are due to present or past exposure. On the other hand, sister chromatid exchanges have a much lower variability in the same individual than urinary mutagenicity. Tucker et al (24) reported a coefficient of variation for sister chromatid exchanges of about $10 \%$. However, if the purpose is to biomonitor accumulated exposure, sister chromatid exchanges may be a more feasible test. Because of high inter- and intraindividual variability, these tests are suitable for examinations at the group level, but not for individual biomonitoring.

Urinary mutagenicity depends on smoking habits. There is no generally accepted model that adjusts for smoking habits (ie, transforms values for nonsmokers to those for smokers or vice versa). Restricting the examination to nonsmokers may not be justifiable, as smokers may have more exposure to cytostatic drugs from, for example, inhaling dust on polluted tobacco. Since these tests are expensive, the optimal design seems to be a matched study, including matching for smoking habits, age, and sex.

\section{Concluding remarks}

Our data indicate that urinary mutagenicity with Salmonella typhimurium TA 98 is the most sensitive of the tests for the biomonitoring of nurses handling cytostatic drugs. Sister chromatid exchanges may also be a usable test, but has the drawback of uncertainty as to whether the changes are attributable to present or past exposure. However, only comparisons of rather large groups make it possible to draw conclusions, and a study design using matched referents would seem optimal.

\section{References}

1. Anderson RW, Puckett WH, Dana WJ, Nguyen TV, Theiss JC, Matney TS. Risk of handling injectable antineoplastic agents. Am J Hosp Pharm 1982;39:1881-7.

2. Bayhan A, Burgaz S, Karakaya AE. Urinary thioether excretion in nurses at an oncologic department. J Clin Pharm Ther 1987;12:303-6.

3. Benhamou S, Callais F, Sancho-Garnier H, Min S, Courtois YA, Festy B. Mutagenicity in urine from nurses handling cytostatic agents. Eur J Cancer Clin Oncol
1986;22:1489-93.

4. Benhamou S, Pot-Deprun J, Sancho-Garnier H, Chouroulinkov I. Sister chromatid exchanges and chromosomal aberrations in lymphocytes of nurses handling cytostatic agents. Int J Cancer 1988;41:350-3.

5. Chrysostomou A, Morley AA, Seshadri R. Mutation frequency in nurses and pharmacists working with cytotoxic drugs. Aust NZ J Med 1984;14:831-4.

6. Falck K, Gröhn P, Sorsa M, Vainio H, Heinonen E, Holsti L. Mutagenicity in urine of nurses handling cytostatic drugs. Lancet 1979;1:1250-1.

7. Kolmodin-Hedman B, Hartvig P, Sorsa M, Falck K. Occupational handling of cytostatic drugs. Arch Toxicol 1983;54:25-33.

8. Jagun O, Ryan M, Waldron HA. Urinary thioether excretion in nurses handling cytotoxic drugs. Lancet 1982; 2:443-44.

9. Nikula E, Kiviniitty K, Leisti J, Taskinen PJ. Chromosome abberrations in lymphocytes of nurses handling cytostatic agents. Scand J Work Environ Health 1984; 10:71-4.

10. Norppa $H$, Sorsa $M$, Vainio $H$, et al. Increased sister chromatid exchange frequencies in lymphocytes of nurses handling cytostatic drugs. Scand J Work Environ Health 1980;6:299-301.

11. Pohlova H, Cerna M, Rössner P. Chromosomal abberrations, SCE and urine mutagenicity in workers occupationally exposed to cytostatic drugs. Mutat Res 1986; $174: 213-17$.

12. Stucker I, Hirsch A, Doloy T, Bastie-Sigeac I, Hemon D. Urine mutagenicity, chromosomal abnormalities and sister chromatid exchanges in lymphocytes of nurses handling cytostatic drugs. Int Arch Occup Environ Health 1986;57:195-205.

13. Waksvik H, Klepp O, Brøgger A. Chromosome analyses of nurses handling cytostatic agents. Cancer Treat Rep 1981;65:607-10.

14. Yager JW, Sorsa M, Selvin S. Micronuclei in cytokinesisblocked lymphocytes as an index of occupational exposure to alkylating cytostatic drugs. In: Bartsch $\mathrm{H}$, Hemminki H, O'Neill IK, ed. Methods for detecting DNA damaging agents in humans: applications in cancer epidemiology and prevention. Lyon: International Agency for Research on Cancer, 1988:213-6. (IARC Scientific Publications; no 89.)

15. Högstedt B. Micronuclei in lymphocytes with preserved cytoplasm - a method for assessment of cytogenetic damage in man. Mutat Res 1984;130:63- 72 .

16. Wolff S, Perry P. Differential giemsa staining of sister chromatids and the study of sister chromatid exchanges without autoradiography. Chromosoma 1974;48:34152.

17. Falck K. Application of the bacterial urinary mutagenicity assay in detection of exposure to genotoxic chemicals [Doctoral dissertation]. Helsinki (Finland): Helsinki University, 1982.

18. O'Connor HJ, Axon ATR, Riley SE, Garner RC. Mutagenicity of gastric juice: the importance of controlling histidine concentration when using Salmonella tester strains. Carcinogenesis 1984;5:853-6.

19. van Doorn R, Bos RP, Leidekkers C-M, WaagenaasZegers MAF, Theuws JLG, Henderson PT. Thioether concentration and mutagenicity of urine from cigarette smokers. Int Arch Occup Environ Health 1979;43: 159-66.

20. Sorsa M, Hemminki K, Vainio H. Occupational exposure to anticancer drugs - potential and real hazards. Mutat Res 1985:154:135-49.

21. Hemminki K, Kyyrönen P, Lindbohm M-L. Spontaneous abortions and malformations in the offspring of nurses exposed to anaesthetic gases, cytostatic drugs, and other potential hazards in hospitals, based on registered information of outcome. J Epidemiol Community 
Health $1985 ; 39: 141-7$.

22. Selevan SG, Lindbohm M-L, Hornung RW, Hemminki K. A study of occupational exposure to antineoplastic drugs and fetal loss in nurses. N Engl J Med 1985;313: 1173-8.

23. Sorsa M, Pyy L, Salomaa S, Nylund L, Yager JW. Biological and environmental monitoring of occupational exposure to cyclophosphamide in industry and hospi- tals. Mutat Res 1988;204:465-79.

24. Tucker JD, Ashworth LK, Johnston GR, Allen NA, Carrano AV. Variation in the human lymphocyte sisterchromatid exchange frequency: results of a long-term longitudinal study. Mutat Res 1988;204:435-44.

Received for publication: 7 March 1990 